\title{
ĐÁNH GIÁ LIÊN QUAN GIỮA CÁC ĐA HÌNH GEN GÂY RỐI LOẠN CHUYỂN HÓA HOMOCYSTEINE VỚI SẢY THAI LIÊN TIẾP
}

\author{
Nguyễn Ngọc Nhất ${ }^{1}$, Trịnh Thế Sơn ${ }^{1}$, Nguyễn Thanh Tùng1, \\ Trần Ngọc Thảo $\mathrm{My}^{2}$, Phạm Đức Minh ${ }^{1}$, Triệu Tiến Sang ${ }^{1}$
}

\section{TÓM TẮT}

Mục tiêu: đánh giá mối liên quan giữa các đa hình gen MTHFR C677T, MTHFR A1298C, MTR A2756G và MTRR A66G gây rối loạn chuyển hóa homocysteine với sảy thai liên tiếp không rõ nguyên nhân ở phụ nữ Việt Nam. Đối tượng và phương pháp nghiên cứu: nghiên cứu bểnh - chứng, đa trung tâm tiến hành trên 92 phụ nữ sảy thai liên tiếp không rõ nguyên nhân và 92 phư nữ khỏe manh. Kết quả: tuổi trung bình của nhóm bệnh và nhóm chứng lần lướt là 29,58 $\pm 2,91$ và $30,69 \pm 2,44$. Allele đôt biến của đa hình MTHFR C677T và MTR A2756G gặp nhiều hơn có ý nghĩa thống kê ở những bệnh nhẩn sảy thai liên tiếp $(p>0,05)$, các đột biến này làm tăng nguy cơ sảy thai liên tiếp lấn lượt là 2,33 và 1,82 lần so với nhóm chứng (OR 2,33; 95\% CI, 1,38-3,96 và OR 1,82; 95\% CI 1,02-3,29). Măt khác, đô̂t biến thay thế nucleotid $A$ thành $C$ ơ gen MTHFR A1298C và thay thế nucleotid $A$ thành $G$ ở gen MTRR A66G không không làm tăng nguy gây bệnh trong nghiên cứu của chúng tôi $(P>0,05)$. Kết luân: đa hình MTHFR C677T và MTR A2756G là yếu tố nguy cơ của sảy thai liên tiếp ở phụ nữ Việt Nam, kết quả này tương đồng với nhiêu nghiên cứu trên thế giới. Trên cơ sở đó chúng tôi kiến nghị tiến hành xét nghiệm phát hiện đa hình gen liên quan chuyển hóa homocysteine ở những người phụ nữ xảy thai liên tiếp chưa rõ nguyên nhân.

Tư khóa: sảy thai liên tiếp, homocysteine, MTHFR C677T, MTHFR A1298C, MTR A2756G, MTRR A66G.

\section{SUMMARY}

EVALUATING THE ASSOCIATION BETWEEN GENETIC POLYMORPHISMS RELATED TO HOMOCYSTEINE METABOLISM AND RECURRENT PREGNANCY LOSS

Objectives: This study aimed to investigate the association between of MTHFR C677T, MTHFR A1298C, MTR A2756G, and MTRR A66G polymorphisms related to homocysteine metabolism among Vietnamese women with unexplained recurrent pregnancy loss. Materials and method: a casecontrol study including 92 women with unexplained recurrent pregnancy loss and 92 healthy controls in multiple centers. Results: The mean age were 29,58 $\pm 2,91$ and 30,69 $\pm 2,44$ for case and control groups, separately. MTHFR C677T and MTR A2756G mutant

\footnotetext{
${ }^{1}$ Học viện Quân y

${ }^{2}$ Faculty of Science and Engineering, Sorbonne University Chịu trách nhiệm chính: Nguyễn Ngọc Nhất

Email: nguyenngocnhat@vmmu.edu.vn

Ngày nhận bài: 6.7.2021

Ngày phản biện khoa học: 31.8.2021

Ngày duyệt bài: 7.9.2021
}

alleles were found to be significantly more prevalent in patients than controls $(p>0,05)$, which led to an increase in the risk of recurrent pregnancy loss as 2.33 and 1.82 fold (OR 2.33; 95\% CI, 1.38-3.96 and OR $1.82 ; 95 \% \mathrm{CI}, 1.02-3.29)$, respectively. Otherwise, A $>\mathrm{C}$ nucleotide alternation for the MTHFR mutation as well as $A>G$ for the MTRR mutation did not show significant risk in our study $(P>0.05)$. Conclusion: MTHFR C677T and MTR A2756G polymorphisms are risk factors of recurrent pregnancy loss in Vietnamese women, these results are similar to that in other studies around the world. According to the association, we recommend genetic testing for women with unexplained recurrent pregnancy loss.

Keywords: recurrent pregnancy loss, homocysteine, MTHFR C677T, MTHFR A1298C, MTR A2756G, MTRR A66G.

\section{I. ĐĂT VẤN ĐỀ}

Sảy thai liên tiếp được định nghĩa là trường hợp mất thai tự nhiên trước tuân thứ 20 xảy ra liến tiếp từ 2 lần trở lên, ảnh hưởng tới 3-5\% phụ nữ trong độ tuổi sinh sản để lại nhiều hệ lụy tiêu cực cho các gia đình và cả xã hội [1]. Có rất nhiều nguyên nhân dẫn tới hiện tượng này ở phụ nữ mang thai như là các bất thường nhiếm sắc, căn nguyên miễn dịch, di dạng tử cung, rối loạn nội tiết, nhiễm trùng, bệnh lý thai kỳ (tăng huyết áp, đái tháo đường), tuổi mẹ cao, cũng như thói quen sống không lành mạnh như uống rượu, hút thuốc. Tuy nhiên, có tới $50 \%$ số trường hợp sảy thai liên tiếp vẫn chưa tìm ra nguyên nhân gây nhiều khó khăn trong điều trị [2].

Một số nghiên cứu gần đây phát hiện ra mối liên quan giữa đa hình gen với sảy thai liên tiếp, tuy nhiên đa hình gen có thực sự là nguyên nhân gây ra sảy thai liên tiếp hay không vẫn còn nhiêu tranh cãi, đặc biệt là đa hình gen gây rối loạn chuyển hóa homocysteine [3]. Đây là một loại axit amin quan trọng có chứa lưu huỳnh, trong chu trình chuyển hóa acid amin này cần sự tham gia của 3 enzyme quan trọng bao gồm methylenetetrahydrofolate reductase (MTHFR), methionine synthase (MTR) và methionine synthase reductase (MTRR). Đa hình gen mã hóa các enzyme trên gây ứ đọng homocystein dẫn tới hiện tượng tăng đông máu, ảnh hưởng tuân hoàn và chức năng của bánh rau cũng như nội mạc tử cung [4]. Gen MTHFR gồm 11 exon, nằm trển nhánh ngắn NST 1p36.3, mã hóa enzyme methylenetetrahydrofolate reductase (MTHFR) 
xúc tác phản ứng một chiều chuyển đổi 5,10methylenetetrahydrofolate thành 5 methyltetrahydrofolate, chất này cung cấp nhóm methyl cho homocysteine tạo ra methione. Đa hình đơn nucleotide C677T (rs1801133) và A1298C (rs1801131) được cho là 2 đột biến chính gây giảm hoạt tính enzyme, thêm vào đó một số nghiên cứu chỉ ra rằng đa hình của MTHFR A1298C làm giảm hoạt động của enzyme ở mức độ thấp hơn so với MTHFR C677T. Ngoài ra, MTRR là enzyme cần thiết để duy trì trạng thái hoạt động của MTR, sự kết hợp của 2 enzyme trên tham gia vào quá trình tái methyl hóa của homocystein thành methionine. Bởi vậy, 2 đa hình MTR A2756G (rs1805087) và MTRR A66G (rs1801394) gây sảy thai liên tiếp cũng được nghiên cứu vào những năm gần đây [5].

Mặc dù vậy, vẫn cần đưa ra thêm bằng chứng để đánh giá mối liên quan giữa các đa hình gen này với sảy thai liên tiếp, hơn thế nữa còn rất ít nghiên cứu đánh giá đồng thời đột biến trên cả 3 gen MTHFR, MTR và MTRR, do vậy chúng tôi tiến hành nghiên cứu đánh giá mối liên quan giữa đột biến MTHFR C677T, MTHFR A1298C, MTR A2756G và MTRR A66G với sảy thai liên tiếp ở phụ nữ Việt Nam.

\section{II. ĐỐI TƯợNG VÀ PHƯƠ'NG PHÁP NGHIÊN CỨU}

2.1 Đối tượng nghiên cứu: Nghiên được tiến hành từ tháng 5/2019-5/2021 trên 184 phụ nữ tuổi từ 18-35 chia thành 2 nhóm: 92 bệnh nhân sảy thai liên tiếp không rõ nguyên nhân và 92 phụ nữ khỏe mạnh.

Tiểu chuẩn lựa chọn: Nhóm bệnh sảy thai liên tiếp từ 2 lần trở lên, nhóm chứng gồm những phụ nữ khỏe mạnh có ít nhất 1 con và không có tiền sử sảy thai.

Tiêu chuẩn loại trừ: Bất thường nhiễm sắc thể, dị dạng tử cung, rối loạn nội tiết, hội chứng kháng phospholipid, bệnh lý thai kỳ (đái tháo đường, tăng huyết áp), nghiện rượu và/hoặc thuốc lá.

\subsection{Phương pháp nghiên cứu:}

Thiết kế nghiên cứu: nghiên cứu bệnh chứng, đa trung tâm.

Các bước tiến hành: Tách chiết $A D N$ tổng

\section{KẾT QUẢ NGHIÊN CỨU}

Bảng 3.1. Đặc điểm đối tượng nghiên cứu

\begin{tabular}{|c|c|c|c|}
\hline & Nhóm bệnh (n=92) & Nhóm chứng (n=92) & Giá trị P \\
\hline Tuổi $($ năm) & $29,58 \pm 2,91$ & $30,69 \pm 2,44$ & 0,0052 \\
\hline Chiều cao $(\mathrm{m})$ & $1,59 \pm 0,04$ & $1,60 \pm 0,05$ & 0,0342 \\
\hline Cân nặng $(\mathrm{kg})$ & $51,11 \pm 3,75$ & $54,38 \pm 4,50$ & 0,0000 \\
\hline BMI $\left(\mathrm{kg} / \mathrm{m}^{2}\right)$ & $20,24 \pm 1,39$ & $21,15 \pm 1,43$ & 0,0000 \\
\hline
\end{tabular}

số từ máu tĩnh mạch: ADN tổng số được tách chiết từ mẫu máu tĩnh mạch theo quy trình của bộ kit G-spin ${ }^{T M}$ Total DNA Extraction Kit (iNtRON Biotechnology - Hàn Quốc). ADN sau tách sẽ được kiểm tra chất lượng (nồng độ và mức độ tinh sạch) bằng máy đo $\mathrm{OD}$ SpectraMax Quickdrop. Kết quả cho thấy, $A D N$ tổng số thu nhận được từ 184 mẫu bệnh phẩm đã đạt chất lượng mong muốn, sẽ được lưu trữ và bảo quản tại nhiệt độ $-20^{\circ} \mathrm{C}$ cho đến khi thực hiện các bước nghiên cứu tiếp theo.

Thực hiện phản ứng Real-time PCR phát hiện đột biến: Hóa chất phản ứng realtime cho mỗi mẫu bệnh phẩm sẽ được chuẩn bị theo yêu cầu của bộ kit Folate Metabolism REAL-TIME PCR Genotyping Kit (DNA-TECHNOLOGY) trong điêu kiện môi trường thích hợp. Phản ứng khuếch đại và phát hiện đột biến đa hình được thực hiện trong hệ thống máy luân nhiệt và tính thời gian thực DTprime 5M1-DNA TECHNOLOGY, với chu trình nhiệt như sau: $80^{\circ} \mathrm{C} / 2$ phút, $94^{\circ} \mathrm{C} / 5$ phút, 5 chu kỳ gồm $94^{\circ} \mathrm{C} / 30$ giây và $67^{\circ} \mathrm{C} / 15$ giây, 45 chu kỳ gồm $94^{\circ} \mathrm{C} / 5$ giây và $67^{\circ} \mathrm{C} / 15$ giây. Sau chu trình khuếch đại và gắn đầu dò, ha nhiệt độ xuống $25^{\circ} \mathrm{C}$ trong vòng 15 giây rồi bắt đầu gia nhiệt từ $25^{\circ} \mathrm{C}$ tới $75^{\circ} \mathrm{C}$ với gia số $1^{\circ} \mathrm{C} /$ chu kỳ, lúc này tín hiệu huỳnh quang sẽ phát ra và được hệ thống máy thu nhận, biểu diển bằng phần mềm dưới dạng đồ thị đường cong nóng chảy. Sau khi chu trình nhiệt kết thúc, đồ thị được ghi nhận và thu thập số liệu để phân tích thống kê.

Các chỉ tiêu nghiên cứu: Đặc điểm cơ bản đối tượng nghiên: như tuổi, chiều cao, cânnặng, BMI. Xác định sự liên quan giữa allele đột biến gây đa hình MTHFR C677T, MTHFR A1298C, MTR A2756G và MTRR A66G với sảy thai liên tiếp ở phụ nữ Việt Nam

Xử lý số liệu: Số liệu được nhập bằng phần mềm Epidata 3.1 và phân tích bằng

STATA 16.0. Kết quả được tình bày dưới dạng giá trị trung bình \pm độ lệch chuẩn và tỉ xuất chênh OR với độ tin cậy 95\%. Student's t test và Chi-square test được sử dụng để kiểm định sự khác nhau của 2 giá trị trung bình, giá trị $\mathrm{p}<$ 0.05 được coi là có ý nghĩa thống kê. 
Tuổi trung bình của những phụ nữ sảy thai liên tiếp là 29,58 $\pm 2,91$ thấp hơn có ý nghĩa thống kê so với nhóm khỏe mạnh không có tiền sử sảy thai 30,69 $\pm 2,44$. Ngoài ra, các đặc điểm cơ bản như chiều cao, cân nặng, BMI nhóm bệnh cũng thấp hơn có ý nghĩa thống kê so với các giá trị tương ứng trong nhóm chứng.
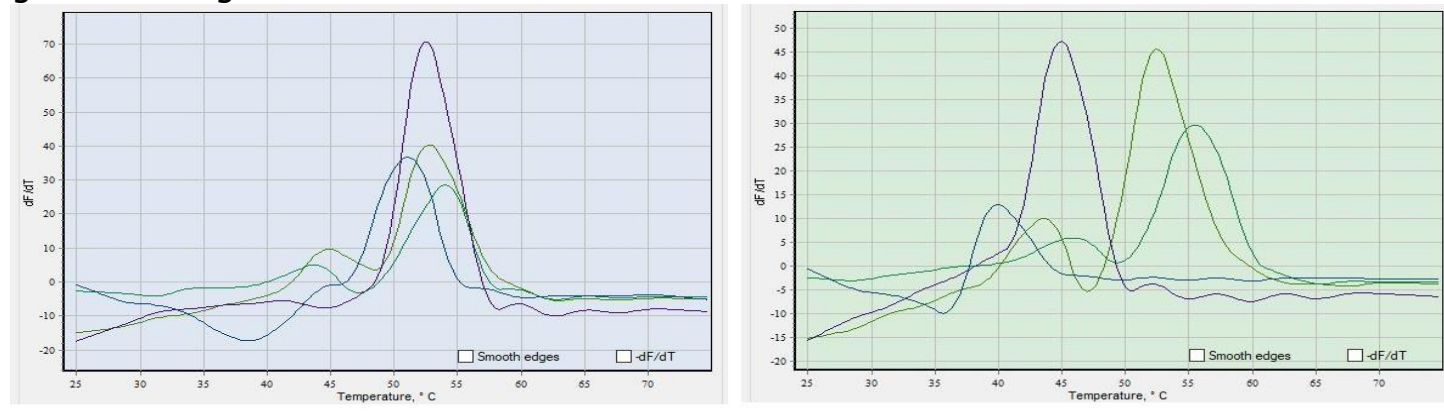

A. Đồ thị kết quà Real-time $\mathrm{PCR}$ kênh màu Fam

B. Đồ thị kết quả Real-time PCR kênh màu Hex

Hình 3.1. Hình minh họa đồ thị kêt quả Real-time PCR 4 đa hình trên một mẫu bệh phẩm

Sau khi phản ứng Real-time PCR phát hiện đa hình gen kết thúc, trên màn hình máy tính sẽ hiện ra lần lượt đồ thị của từng kênh màu Fam và Hex, biểu diễn đường cong nóng chảy mỗi đa hình gen của một mẫu bệnh phẩm.

Bảng 3.2. P̉hân bố các kiểu gen của 4 đa hình trong nhóm bệnh và nhóm chứng

\begin{tabular}{|c|c|c|}
\hline & Nhóm bệnh $(\mathbf{n = 9 2})$ & Nhóm chứng (n=92) \\
\hline Gen MTHFR C677T: Bình thường & $42(45,65 \%)$ & $64(69,57 \%)$ \\
Dị hợp đột biến & $41(44,57 \%)$ & $25(27,17 \%)$ \\
Đồng hợp đột biến & $9(9,78 \%)$ & $3(3,26 \%)$ \\
\hline Gen MTHFR A1298C: Bình thường & $45(48,91 \%)$ & $48(52,17 \%)$ \\
Dị hợp đột biến & $38(41,30 \%)$ & $37(40,22 \%)$ \\
Đồng hợp đột biến & $9(9,78 \%)$ & $7(7,61 \%)$ \\
\hline Gen MTR A2756G: Bình thường & $56(60,87 \%)$ & $68(73,91 \%)$ \\
Dị hợp đột biến & $31(33,70 \%)$ & $23(25,00 \%)$ \\
Đồng hợp đột biến & $5(5,43 \%)$ & $1(1,09 \%)$ \\
\hline Gen MTRR A66G: Bình thường & $45(48,91 \%)$ & $49(53,26 \%)$ \\
Dị hợp đột biến & $34(36,96 \%)$ & $36(39,13 \%)$ \\
Đồng hợp đột biến & $13(14,13 \%)$ & $7(7,61 \%)$ \\
\hline
\end{tabular}

Trong nghiên cứu này, chúng tôi sử dụng kỹ thuật HRM đế phát hiện các đột biến đa hình đơn nucleotide, từ đó thu được bảng kết quả kiểu gen của đối tượng nghiên cứu. Đối với cả $4 \mathrm{gen}$, nhận thấy số người mang kiểu gen di hợp, đồng hợp bệnh ở nhóm sảy thai liên tiếp đều cao hơn kết quả tương ứng ở nhóm phụ nữ khỏe mạnh.

Bảng 3.3. Phân bố các allele của đa hình trong nhóm bệnh và nhóm chứng

\begin{tabular}{|c|c|c|c|c|}
\hline & $\begin{array}{l}\text { Nhóm bệnh } \\
(n=92)\end{array}$ & $\begin{array}{c}\text { Nhóm chứng } \\
(n=92)\end{array}$ & OR (95\%CI) & Giá trị P \\
\hline $\begin{array}{r}\text { Gen MTHFR C677T: Allele C } \\
\text { Allele T }\end{array}$ & $\begin{array}{c}125(67,94 \%) \\
59(32.06 \%)\end{array}$ & $\begin{array}{c}153(83,15 \%) \\
31(16,85 \%)\end{array}$ & $\begin{array}{c}1 \\
2,33(1,38-3,96)\end{array}$ & 0,007 \\
\hline $\begin{array}{r}\text { Gen MTHFR A1298C: Allele A } \\
\text { Allele C }\end{array}$ & $\begin{array}{c}128(69,57 \%) \\
56(30,43 \%)\end{array}$ & $\begin{array}{c}133(72,28 \%) \\
51(27,72 \%)\end{array}$ & $\begin{array}{c}1 \\
1,14(0,71-1,84)\end{array}$ & 0 \\
\hline $\begin{array}{r}\text { Gen MTR A2756G: Allele A } \\
\text { Allele G }\end{array}$ & $\begin{array}{c}143(77,72 \%) \\
41(22,28 \%)\end{array}$ & $\begin{array}{c}159(86,41 \%) \\
25(13,59 \%)\end{array}$ & $\begin{array}{c}1 \\
1,82(1,02-3,29)\end{array}$ & 0,0297 \\
\hline $\begin{array}{r}\text { Gen MTRR A66G: Allele A } \\
\text { Allele G }\end{array}$ & $\begin{array}{c}123(66,85 \%) \\
61(33,15 \%)\end{array}$ & $\begin{array}{c}131(91,19 \%) \\
53(28,80 \%)\end{array}$ & $\begin{array}{c}1 \\
1,23(0,77-1,96)\end{array}$ & 0,3671 \\
\hline
\end{tabular}

Tần số allele T của đa hình MTHFR C677T cao hơn có ý nghĩa thống kê ở nhóm sảy thai liên tiếp không rõ nguyên nhân so với nhóm chứng, phân tích thống kê cho thấy đột biến thay thế nucleotid $\mathrm{C}$ bằng $\mathrm{T}$ ở vị trí này sẽ làm tăng nguy cơ sảy thai liên tiếp lên 2,33 lần (OR 2,33; 95\% CI, 1,38-3,96; $p=0,007$ ).

Tương tự đối với đa hình MTR A2756G, tần số allele $\mathrm{G}$ trong nhóm bệnh cao hơn có ý nghĩa thống kê so với nhóm chứng, đồng thời từ kết 
quả phân tích có thể thấy rằng khi xảy ra đột biến thay thế nucleotid $A$ thành $G$ ở vị trí 2756 của gen MTR thì nguy cơ sảy thai liên tiếp tăng 1,82 lần (OR 1,82; 95\% CI, 1,02-3,29; P = 0,0297).

Mặt khác, đột biến thay thế nucleotid $A$ thành $C$ ở cả gen MTHFR A1298C và thay thế nucleotid $A$ thành G ở gen MTRR A66G tạo thành allele đột biến đều không làm tăng nguy cơ sảy thai liên tiểp ở những phụ nữ tham gia nghiên cứu $(P>0,05)$.

\section{BÀN LUÂ̂N}

Sảy thai liên tiếp vẫn đang là thách thức lớn đối với y học hiện nay, không chỉ trong hỗ trợ sinh sản và cả tâm lý học. Những nguyên nhân gây bệnh được tìm ra như bất thường nhiễm sắc thể mẹ, bệnh lý miễn dịch như hội chứng kháng phospholipid, dị dạng tử cung... mẹ cao tuổi hoặc những thói quen sống không lành mạnh đã được chúng minh như nghiện rượu, hút thuốc lá. Tuy vậy, vẫn còn tới $50 \%$ các trường hợp bệnh sảy ra mà không rõ nguyên nhân, do vậy không có phương pháp can thiệp đặc hiệu. Gần đây, các kỹ thuật trong di truyền phát triển góp phần tìm ra lời giải cho những trường hợp trên, theo đó đa hình gen gây rối loạn chuyển hóa homocystein là yếu tố nguy cơ hàng đầu cần được nghiên cứu. MTHFR C677T, A1298C đều khiến cho enzyme tham gia vào quá trình chuyển hóa homocyesteine bị giảm hoạt tính, hay đối với đa hình gen MTR và MTRR thì cũng ảnh hưởng nặng nề tới quá trình methyl hóa $A D N$ và histone [6]. Chính vì vậy, mối liên hệ giữa chúng và hiện tượng sảy thai liên tiếp luổn được ưu tiên nghiên cứu chuyên sâu, số liệu về kiểu gen ngày càng thêm đa dạng tuy nhiên kết quả thu được vẫn còn nhiều tranh cãi do khác biệt về cỡ mẫu, đối tượng nghiên cứu cũng như một số yếu tố khách quan.

Nghiên cứu của chúng tôi cho thấy đa hình gen MTHFR C677T và MTR A2756G có liên quan tới hiện tượng sảy thai liên tiếp ở phụ nữ Việt Nam. Kết quả này phù hợp với nhiều nghiên cứu trước đó trên thế giới, đặc biệt tập trung nhiều vào gen MTHFR. Gen này có vai trò quan trọng trong methyl hóa homocysteine và tổng hợp DNA, ngoài ra khi di truyền sang thế hệ sau gầy giảm khả năng làm tổ và phát triển của phôi thai. Bắt đầu tữ những nghiên cứu năm 1997 và cho đến gần đây nhất là năm 2020, đa số nghiên cứu nhận thấy tần số xuất hiện allele $T$ và allele C giữa nhóm phụ nữ bị sảy thai và nhóm phụ nữ có tiền sử sinh con bình thường có sự khác biệt mang ý nghĩa thống kê. Một số nghiên cứu chỉ ra rằng allele $T$ có liên quan đến hiện tượng sảy thai, tuy nhiên một số khác đưa ra kết quả ngược lại hoàn toàn. Điều này có thể lí giải bởi sự khác biệt từ nguồn gốc của những người tham gia nghiên cứu cũng như về độ tuổi sinh sản của họ khi sảy thai. Tần số allele của những đa hình này ở những quần thể khác nhau như là quần thể người Đông Á, quần thể người Nam Á hay châu Âu đều thể hiện sự thay đổi rõ rệt, và từ đó một phần ảnh hưởng tới kết quả của những nghiên cứu này [2], [7].

Tuy phần lớn các đề tài tập trung vào đa hình gen MTHFR, vào thời gian gần đây gen MTR bắt đầu nhận được nhiều quan tâm từ giới chuyên môn bởi ảnh hưởng của nó đang ngày càng được hiểu rõ hơn trong cơ chế điều hòa nông độ homocysteine gây sảy thai liên tiếp. Theo Asadnejad và cộng sự, đa hình A2756G liên quan đến enzyme methionine synthase có liên quan tới khả năng thai phụ bị sảy thai nhiều lần ở vùng bắc Iran, cụ thể hơn allele $\mathrm{G}$ xuất hiện ở nhóm bệnh đến $28 \%$, con số này cao hơn nhiều so với $19 \%$ ở nhóm chứng [8]. Kết quả này tương đương với nghiên cứu của chúng tôi khi tần xuất của allele đột biến $\mathrm{G}$ ở nhóm bệnh là $22,28 \%$ cao hơn có ý nghĩa thống kê so với nhóm chứng là $13,59 \%$.

Đối với hai đa hình gen MTHFR A1298C và MTRR A66G, số liệu thống kê thu nhận được trong nghiên cứu này cho thấy các đa hình này không liên quan tới sảy thai liên tiếp ở phụ nữ Việt Nam. Trên thế giới, rất nhiều đề tài được thực hiện để tìm hiểu sâu hơn về đa hình c.1298A >C nhưng một lần nữa, ảnh hưởng của nó còn để lại nhiều tranh cãi. Điều tương tự cũng xảy ra đối với đa hình c.66A>G của gen MTRR khi mà sự khác biệt về mặt kết quả một phần nằm ở sự phân bố của kiểu gen và tần số allele giữa các vùng đặc trưng [7], [9]. Mặc dù vậy, cần phải đầu tư nghiên cứu nhiều hơn nữa về ảnh hưởng thực sự của nó tới sảy thai, đặc biệt chú trọng nghiên cứu trên nhiều nhóm đối tượng đa dạng về mặt nguồn gốc và vị trí địa lý.

\section{KẾT LUẬN}

Mối liên quan giữa đa hình gen liên quan đến quá trình chuyển hóa homocysteine với bệnh cảnh sảy thai liên tiếp vẫn cần tiếp tục nghiên cứu để đi đến đồng thuận chung. Việc phát hiện những yếu tố liên quan đến chuyển hóa homocysteine đã và đang đặt nền móng trong việc xây dựng một phác đồ tư vấn sàng lọc và điều trị hỗ trợ sinh sản hiệu quả.

\section{TÀI LIẸU THAM KHẢO}

1. Practice Committee of the American Society 
for Reproductive Medicine (2013). Definitions of infertility and recurrent pregnancy loss: a committee opinion. Fertil Steril, 99(1), 63.

2. Y $X_{\text {., }} Y$ B., $L$ R. và cộng sự. (2019). Relationship between unexplained recurrent pregnancy loss and 5,10methylenetetrahydrofolate reductase) polymorphisms. Fertil Steril, 111(3).

3. Chen H., Yang X., và Lu M. (2016). Methylenetetrahydrofolate reductase gene polymorphisms and recurrent pregnancy loss in China: a systematic review and meta-analysis. Arch Gynecol Obstet, 293(2), 283-290.

4. Kjaergaard A.D., Wu Y., Ming W.-K. và cộng sự. (2021). Homocysteine and female fertility, pregnancy loss and offspring birthweight: a twosample Mendelian randomization study. Eur J Clin Nutr.

5. Li X., Jiang J., Xu M. và cộng sự. (2015). Individualized supplementation of folic acid according to polymorphisms of methylenetetrahydrofolate reductase (MTHFR), methionine synthase reductase (MTRR) reduced pregnant complications. Gynecol Obstet Invest, 79(2), 107-112.

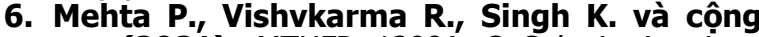
sư.' (2021). MTHFR $1298 A>C$ Substitution is a Strong Candidate for Analysis in Recurrent Pregnancy Loss: Evidence from 14,289 Subjects. Reprod Sci Thousand Oaks Calif.

7. Ahangari N., Doosti M., Mousavifar N. và cộng sự. (2019). Hereditary thrombophilia genetic variants in recurrent pregnancy loss. Arch Gynecol Obstet, 300(3), 777-782.

8. Association of the methionine synthase gene polymorphism with recurrent miscarriage in Mazandaran province, Iran | New Zealand Journal of Medical Laboratory Science. <https:// search.informit.org/doi/abs/10.3316/INFORMIT.72 3673042076897> accessed: 24/09/2021.

9. Zhang Y., Zhan W., Du Q. và cộng sự. (2020). Variants C.677 C>T, c. $1298 \mathrm{~A}>\mathrm{C}$ in MTHFR, and c.66 $\mathrm{A}>\mathrm{G}$ in MTRR Affect the Occurrence of Recurrent Pregnancy Loss in Chinese Women. Genet Test Mol Biomark, 24(11), 717-722.

\title{
KIẾN THỨC VỀ PHÒNG NGỪA CHUẨN CỦA SINH VIÊN NĂM CUỐI TRƯỜNG ĐẠI HỌC Y HÀ NộI NĂM 2021
}

\author{
Bùi Văn Tùng', Bùi Vũ Bình', \\ Phạm Tùng Sơn ${ }^{1}$, Bùi Thị Diệu Huyền ${ }^{2}$, Lê Thị Hoàn ${ }^{1}$
}

\section{TÓM TẮT}

Mục tiêu: Mô tả kiến thức về phòng ngừa chuẩn (PNC) và một số yếu tố liên quan của sinh viên năm cuối trường Đại học Y Hà Nội năm 2020. Đối tượng và phương pháp nghiên cứu: Nghiên cứu được thực hiện trên 444 sinh viên năm cuối trường đại học Y Hà Nối thời gian từ 03/2021 đến 08/2021. Kết quả: Tỷ lệ sinh viên có kiến thức đạt là $64,2 \%$. Các yếu tố liên quan đước xác đinh như chuyên ngành cử nhân thuộc nhóm khác có tỷ lệ kiến thức đạt chỉ bằng 0,22 lần so với chuyên ngành cử nhân điều dưỡng (aOR = 0,22; 95\%CI: 0,11 - 0,44). Đối tượng được nhận tài liệu vê PNC trước đây có tỷ lệ kiến thức đạt cao gấp 2,33 lần so với đối tượng chưa được nhận tài liệu về PNC (aOR = 2,33; 95\%CI: 1,51-3,58). Kết luận: Tỷ lệ kiến thức về PNC của sinh viên tương đối thấp. Các yếu tố liên quan xác định được cần được chú ý khi tiến hành xây dựng chương trình đào tạo về PNC ở nhóm đối tượng này.

Tư khóa: Kiến thức, phòng ngừa chuẩn, sinh viên y khoa.

Chữ viêt tắt: Phòng ngừa chuẩn (PNC)

\footnotetext{
${ }^{1}$ Trường Đại học Y Hà Nội

${ }^{2}$ Dai hoc Y Dước Thái Binh

Chịu trách nhiệm chính: Lê Thị Hoàn

Email: lethihoan@hmu.edu.vn

Ngày nhận bài: 7.7.2021

Ngày phản biện khoa học: 31.8.2021

Ngày duyệt bài: 8.9 .2021
}

\section{SUMMARY \\ KNOWLEDGE OF STANDARD PRECAUTIONS AMONG SENIOR STUDENTS OF HA NOI MEDICAL UNIVERSITY IN 2021}

Objectives: To describe knowledge about standard precaution and some associated factors among final year students of Hanoi Medical University in 2020. Subjects and methods: We conducted a study among 444 the final year students of Hanoi Medical University from March 2021 to August 2021. Results: The results show that the proportion of students with knowledge of standard precautions is $64,2 \%$. There is a relationship between training majors and received prior standard precaution material with standard precautions knowledge status. The other bachelor was under 0.22 times less likely $(\mathrm{aOR}=0.22 ; 95 \% \mathrm{CI}: 0.11-0.44)$ to achieve a higher standard precaution compared to nursing students. Students who received documents on standard precaution in the past were over 2.33 times more likely $(\mathrm{aOR}=2.33 ; 95 \% \mathrm{CI}: 1.51-3,58)$ to achieve a higher standard precaution than those who did not receive documents about standard precaution. Conclusions: Medical universities should incorporate standard prevention programs for all disciplines in their clinical training with a handout approach, selfreading for students.

Key word: Knowledge, standard precautions, medical students

\section{I. ĐẶT VẤN ĐỀ}

Trong qua trình làm việc tại bệnh viện nhân 